\title{
Establishment of Culex modestus in Belgium and a Glance into the Virome of Belgian Mosquito Species
}

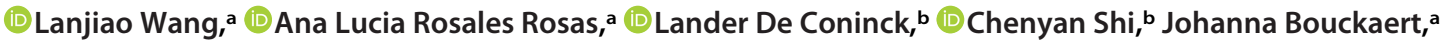 \\ (D) Jelle Matthijnssens, ${ }^{b}$ (D) Leen Delang ${ }^{a}$
}

aKU Leuven Department of Microbiology, Immunology and Transplantation, Rega Institute for Medical Research, Laboratory of Virology and Chemotherapy, Leuven, Belgium

bLaboratory of Viral Metagenomics, Rega Institute for Medical Research, KU Leuven, Leuven, Belgium

Lanjiao Wang and Ana Lucia Rosales Rosas contributed equally to this work. Author order was determined on the basis of seniority.

\begin{abstract}
Culex modestus mosquitoes are considered potential transmission vectors of West Nile virus and Usutu virus. Their presence has been reported across several European countries, including one larva detected in Belgium in 2018. In this study, mosquitoes were collected in the city of Leuven and surrounding areas in the summers of 2019 and 2020. Species identification was performed based on morphological features and partial sequences of the mitochondrial cytochrome oxidase subunit I (COI) gene. The 107 mosquitoes collected in 2019 belonged to eight mosquito species, Culex pipiens (24.3\%), Cx. modestus (48.6\%), Cx. torrentium (0.9\%), Culiseta annulata $(0.9 \%)$, Culiseta morsitans (0.9\%), Aedes sticticus (14.0\%), Aedes cinereus (9.3\%), and Anopheles plumbeus (0.9\%), suggesting the presence of an established $C X$. modestus population in Belgium. The collection of $C x$. modestus mosquitoes at the same locations in 2020 confirmed their establishment in the region. Haplotype network analysis of the $\mathrm{CO}$ sequences for $C x$. modestus showed that the Belgian population is rather diverse, suggesting that it may have been established in Belgium for some time. The Belgian $C x$. modestus population was most closely related to populations from the United Kingdom and Germany. Characterization of the virome of the collected mosquitoes resulted in the identification of at least 33 eukaryotic viral species. Nine (nearly) complete genomes belonging to 6 viral species were identified, all of which were closely related to known viruses. In conclusion, here, we report the presence of $C x$. modestus in the surrounding areas of Leuven, Belgium. As this species is considered to be a vector of several arboviruses, the implementation of vector surveillance programs to monitor this species is recommended.
\end{abstract}

IMPORTANCE Culex modestus mosquitoes are considered to be a potential "bridge" vector, being able to transmit pathogens between birds as well as from birds to mammals, including humans. In Belgium, this mosquito species was considered absent until the finding of one larva in 2018 and subsequent evidence of a large population in 2019 to 2020 described here. We collected mosquitoes in the summers of 2019 and 2020 in the city of Leuven and surrounding areas. The mosquito species was identified by morphological and molecular methods, demonstrating the presence of $C x$. modestus in this region. The ability of mosquitoes to transmit pathogens can depend on several factors, one of them being their natural virus composition. Therefore, we identified the mosquito-specific viruses harbored by Belgian mosquitoes. As CX. modestus is able to transmit viruses such as West Nile virus and Usutu virus, the establishment of this mosquito species may increase the risk of virus transmission in the region. It is thus advisable to implement mosquito surveillance programs to monitor this species.
Citation Wang L, Rosales Rosas AL, De Coninck L, Shi C, Bouckaert J, Matthijnssens J, Delang L. 2021. Establishment of Culex modestus in Belgium and a glance into the virome of Belgian mosquito species. mSphere 6:e122920. https://doi.org/10.1128/mSphere.01229-20. Editor John Schoggins, University of Texas Southwestern Medical Center

Copyright $\odot 2021$ Wang et al. This is an openaccess article distributed under the terms of the Creative Commons Attribution 4.0 International license. Address correspondence to Leen Delang, leen.delang@kuleuven.be.

Received 1 December 2020

Accepted 24 March 2021

Published 21 April 2021 
- he mosquito species Culex modestus was described for the first time by Eugenio

Ficalbi in northern Italy in 1889 (1) and is considered a rare species. In Europe, this species is distributed mainly in southern and central European countries. Field collection studies have reported the presence of $C_{x}$. modestus in France, Spain, Portugal, Germany, Romania, Serbia, the Czech Republic, and, more recently, in more northern countries such as the United Kingdom, Denmark, and Sweden (2-5). In Belgium, this mosquito species was thought to likely be present given its occurrence in nearby countries (6). Until now, only one larva has been found in 2018 and identified through molecular methods (7). Recent field studies in the United Kingdom have confirmed two characteristics of $C x$. modestus, (i) its ornithophilic habit, i.e., feeding on resident and migratory bird species (8), and (ii) its mammalophilic and anthropophilic feeding behavior, showing that $C x$. modestus is also a major human-biting mosquito species similar to Culex pipiens (9). Thus, $C x$. modestus could play a role in nature as a "bridge" vector, being able to transmit pathogens between birds in an enzootic cycle as well as from birds to mammals, including humans, in an epizootic/epidemic cycle.

Previous studies of different $C x$. modestus populations in Europe revealed that this species can act as a carrier of different pathogens and is likely able to transmit these pathogens as well. In the south of France, $C x$. modestus mosquitoes have been found to serve as amplifying vectors for seasonal West Nile virus (WNV), introduced by migratory birds (10). Cx. modestus mosquitoes collected in the Danube Delta region (border of Romania and Ukraine) were positive for Plasmodium sp. lineage Donana03 (avian malaria) (11). In addition, a prevalence of trypanosomatids of $5.1 \%$ was detected in the gut of CX. modestus collected in the Czech Republic between 1998 and 2002 (12). Furthermore, $C x$. modestus is the vector and reservoir of Lednice virus (LEDV), a rare bunyavirus that causes viremia in wild birds. During the last 60 years, various European countries have reported the presence of LEDV in their $C x$. modestus mosquito populations (13). Besides LEDV, Tahyna virus (TAHV) has also been isolated from $C x$. modestus in Czechoslovakia and France (14).

Mosquito surveillance in the United Kingdom started focusing on Cx. modestus due to its confirmed establishment and important role in the transmission of WNV and Usutu virus (USUV) (15). The role in WNV transmission in Europe was demonstrated by the detection of WNV in this mosquito species during an outbreak in the Sardinia region of Italy in 2011 (16). During this outbreak, the circulating virus strains belonged to lineage 1. This was the first report of an Italian WNV strain that caused clinical signs in the affected birds. The mosquito survey carried out in this area revealed that these virus strains were found in $C x$. modestus mosquitoes. During the mosquito seasons of 2015 and 2016, WNV lineage 2 was also detected in Cx. modestus mosquitoes collected in the Lednice-Valtice area in southern Moravia $(17,18)$. Regarding the vector competence of $C x$. modestus for WNV, this mosquito species was found to be competent to transmit WNV experimentally. More than $90 \%$ of $C x$. modestus mosquitoes developed disseminated infection 14 days after an infectious WNV blood meal (19). Moreover, it is considered an extremely efficient vector given that the dissemination rate and the transmission rate reached $89.2 \%$ and $54.5 \%$, respectively, after 14 days of incubation (20).

USUV has also been detected in field-collected $C x$. modestus mosquitoes, likely cocirculating with WNV (21). USUV is another arbovirus of African origin that is principally transmitted by Culex mosquitoes. This virus belongs to the genus Flavivirus, along with dengue virus, yellow fever virus, Zika virus, Japanese encephalitis virus, and WNV (22). The virus is maintained in an enzootic cycle between ornithophilic mosquitoes and birds. In Europe, USUV was found in a retrospective analysis of archived tissue samples from bird deaths in the Tuscany region of Italy in 1996 (23). In 2001, USUVassociated death of blackbirds was reported in Austria (24), Germany, and the Netherlands $(25,26)$. In 2016, numerous wild birds, mainly Eurasian blackbirds (Turdus merula), were affected by a USUV outbreak in Belgium in the provinces of Limburg, Antwerp, and Flemish Brabant (27). In 2017, the virus further spread to the west, and 
A)

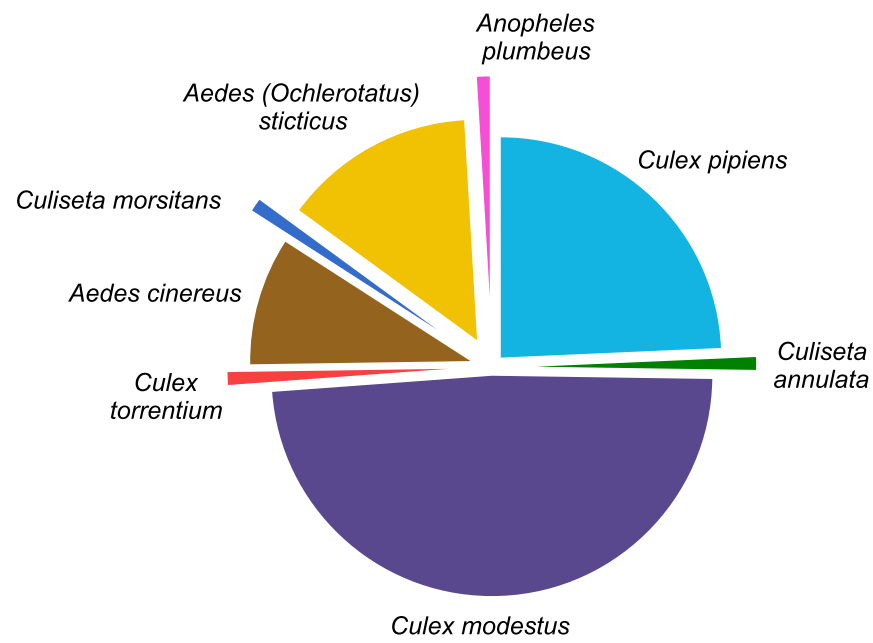

B)
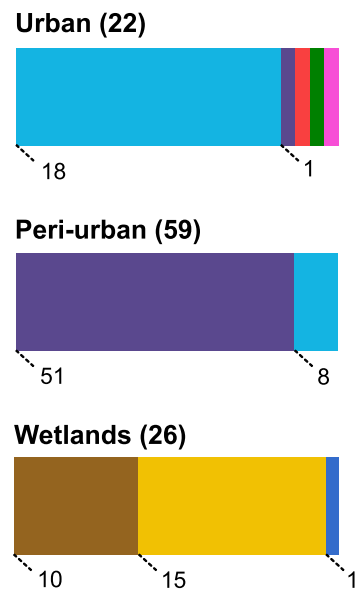

FIG 1 Mosquito species collected in Leuven, Belgium, in 2019. (A) Distribution of mosquito species captured during the summer of 2019 across all locations sampled in Leuven. (B) Distribution of mosquito species across habitat types in Leuven. Mosquito species are marked in different colors. The number of specimens is indicated in the bar chart.

by the summer of 2018, the whole country was affected (28). Despite the recent USUV outbreaks, it is not known which mosquito species are the vectors of USUV in Belgium. To gain insight into which mosquito species might carry clinically relevant viruses, we collected field mosquitoes using BG-Sentinel traps in the city of Leuven and its surrounding areas in three different environment types (urban, periurban, and wetland areas).

To unravel the high diversity of mosquito-specific viruses (MSVs) harbored by Belgian mosquitoes, we performed a metagenomic sequencing approach using the novel enrichment technique of viromes (NetoVIR) protocol (29). The study of viral diversity in mosquitoes is important since MSVs have the potential to modulate the vector competence of mosquitoes for different arboviruses (30). The virome of tropical mosquito species such as Aedes aegypti has been studied extensively. On the other hand, knowledge of the viral diversity in mosquitoes from more temperate regions is still scarce but increasing. For instance, a recent virome study identified novel RNA viruses in Swedish mosquitoes (31). However, the virome of mosquitoes from Western Europe, including Belgium, has not yet been studied. Therefore, we provide a first glance into the virome of mosquitoes collected in Belgium.

\section{RESULTS}

Mosquito species detected in Leuven, Belgium. A total of 107 mosquito specimens were collected in three distinct locations in Leuven in the summer of 2019. According to the DNA barcodes generated and morphological features, these mosquitoes belonged to eight mosquito species: Culex pipiens (24.3\%), Cx. modestus (48.6\%), Cx. torrentium (0.9\%), Culiseta annulata (0.9\%), Culiseta morsitans (0.9\%), Aedes sticticus (14.0\%), Aedes cinereus (9.3\%), and Anopheles plumbeus (0.9\%) (Fig. 1A). Surprisingly, Cx. modestus accounted for $\sim 50 \%$ of all collected mosquitoes in three different breeding sites. Culex species were predominant in urban and periurban areas, whereas specimens found in the water reservoir wetlands belonged mostly to the genus Aedes (Fig. 1B).

Establishment of $C_{x}$. modestus in Leuven, Belgium. A maximum likelihood (ML) tree was built from the $C x$. modestus cytochrome oxidase subunit I (COI) barcodes obtained in Leuven and COI sequences of 20 other culicid species described previously (6). Cx. modestus barcodes from Leuven clustered with two reference $C x$. modestus sequences that were included (GenBank accession numbers KJ401305 and MK971991). 


\section{Culex modestus sequences}

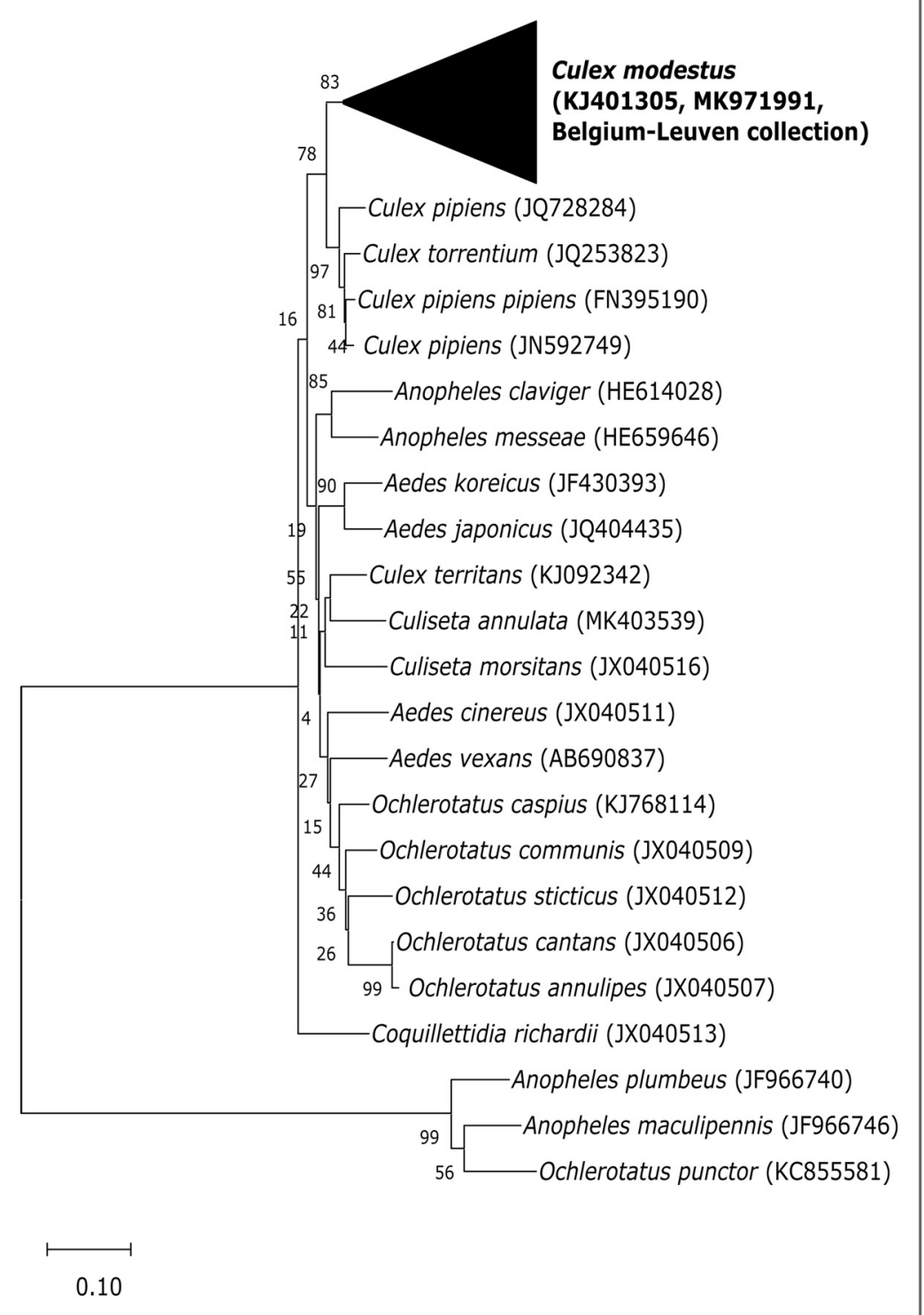

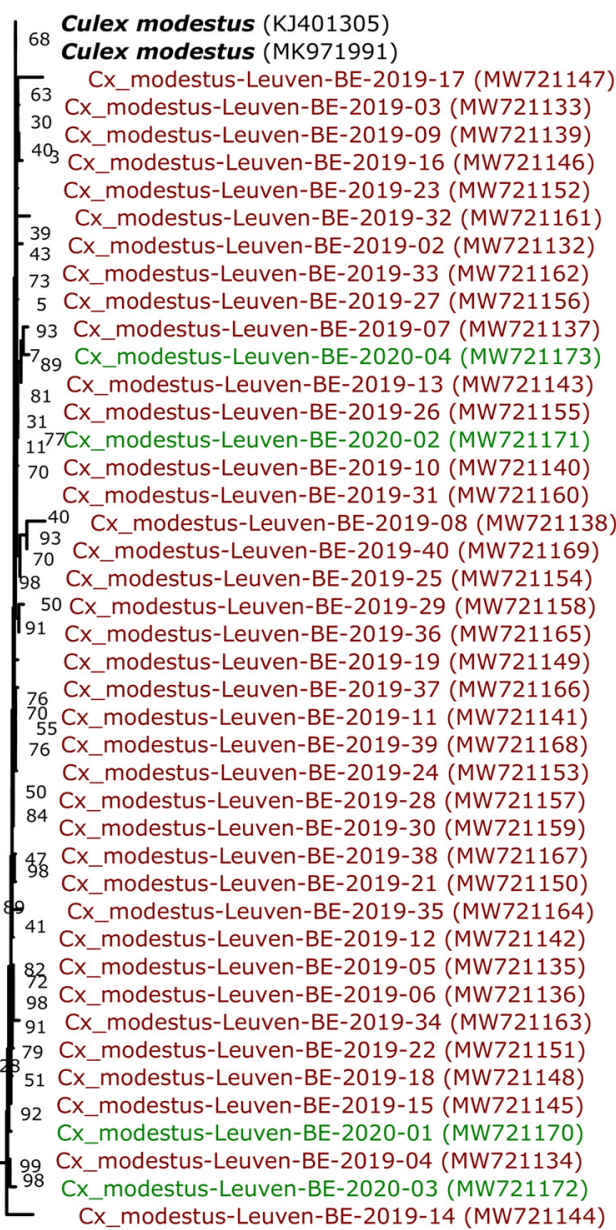

\section{3}

FIG 2 ML tree of the COI sequences of 21 culicid species. Sequences derived from mosquitoes collected in Leuven are collapsed with the reference sequences for $C x$. modestus. The collapsed branch is expanded in the panel on the right. GenBank accession numbers are in parentheses.

All sequences for $C x$. modestus fell within one large well-supported monophyletic cluster, separated from other mosquito species, which suggests that they belong to the same species (Fig. 2). To find out whether $C x$. modestus is established in the region, field collections were performed in the summer of the consecutive year (2020) using the same geographic locations as the ones used previously. Again, Cx. modestus mosquitoes were retrieved (Fig. 2), confirming the establishment of this mosquito species in the area of Leuven.

Haplotype network of $\mathbf{C x}$. modestus mosquitoes. The data set analyzed for haplotype inference was constructed by employing $184 \mathrm{Cx}$. modestus partial COI sequences retrieved from the $\mathrm{NCBI}$ database corresponding to eight European countries and including 40 partial high-quality $\mathrm{COI}$ sequences obtained from the molecular identification of field-collected mosquitoes in Leuven (see Tables S2 to S4 in the supplemental 
TABLE 1 Haplotype and nucleotide diversity of $C x$. modestus from 9 countries in Europe

\begin{tabular}{lllll}
\hline $\begin{array}{l}\text { Location of } \\
\text { population }\end{array}$ & $\begin{array}{l}\text { No. of } \\
\text { samples }\end{array}$ & $\begin{array}{l}\text { No. of } \\
\text { haplotypes }\end{array}$ & $\begin{array}{l}\text { Mean haplotype } \\
\text { diversity } \pm \text { SD }\end{array}$ & $\begin{array}{l}\text { Mean nucleotide } \\
\text { diversity } \pm \text { SD }\end{array}$ \\
\hline Belgium & 44 & 33 & $0.9852 \pm 0.0082$ & $0.0270 \pm 0.0136$ \\
Denmark & 7 & 7 & $1.0000 \pm 0.0764$ & $0.0174 \pm 0.0103$ \\
France & 28 & 11 & $0.8598 \pm 0.0462$ & $0.0069 \pm 0.0039$ \\
Germany & 42 & 17 & $0.9013 \pm 0.0278$ & $0.0113 \pm 0.0060$ \\
Portugal & 2 & 2 & $1.0000 \pm 0.5000$ & $0.0065 \pm 0.0073$ \\
Serbia & 4 & 4 & $1.0000 \pm 0.1768$ & $0.0182 \pm 0.0125$ \\
Spain & 22 & 8 & $0.8182 \pm 0.0586$ & $0.0058 \pm 0.0034$ \\
Sweden & 5 & 5 & $1.0000 \pm 0.1265$ & $0.0085 \pm 0.0058$ \\
UK & 74 & 28 & $0.9252 \pm 0.0176$ & $0.0107 \pm 0.0057$ \\
\hline
\end{tabular}

material). Four partial $\mathrm{COI}$ sequences from mosquitoes collected during the summer of 2020 were included as well.

Among the $228 \mathrm{COI}$ sequences ( $639 \mathrm{bp}$ ), 97 haplotypes were found. The majority of haplotypes (88) were present only in the country of origin, while only 9 haplotypes were shared by two or more countries. Haplotype diversity ranged from 0.8182 in Spain to 1.000 in Denmark, Portugal, Serbia, and Sweden (Table 1). This analysis revealed that haplotype diversity in Belgium was the second highest (0.9852) of all countries screened, followed by the United Kingdom (0.9252) and Germany (0.9013). Nucleotide diversity estimations ranged from 0.0058 in Spain to 0.0270 in Belgium. Belgium exhibited a nucleotide diversity of 0.0270 , which can be considered moderate but which is the highest in all included European countries.

Mitochondrial DNA genealogy of $C x$. modestus. The median-joining (MJ) network displayed the ancestry of $C x$. modestus mosquitoes (Fig. 3), where two lineages were visualized, separated by 1 mutation step. Haplotypes from Spain and Portugal were found uniquely in lineage I, while haplotypes from Germany, the United Kingdom, Belgium, and Sweden predominated in lineage II. Haplotypes from France, Serbia, and Denmark were scattered across both lineages. The majority of haplotypes that were

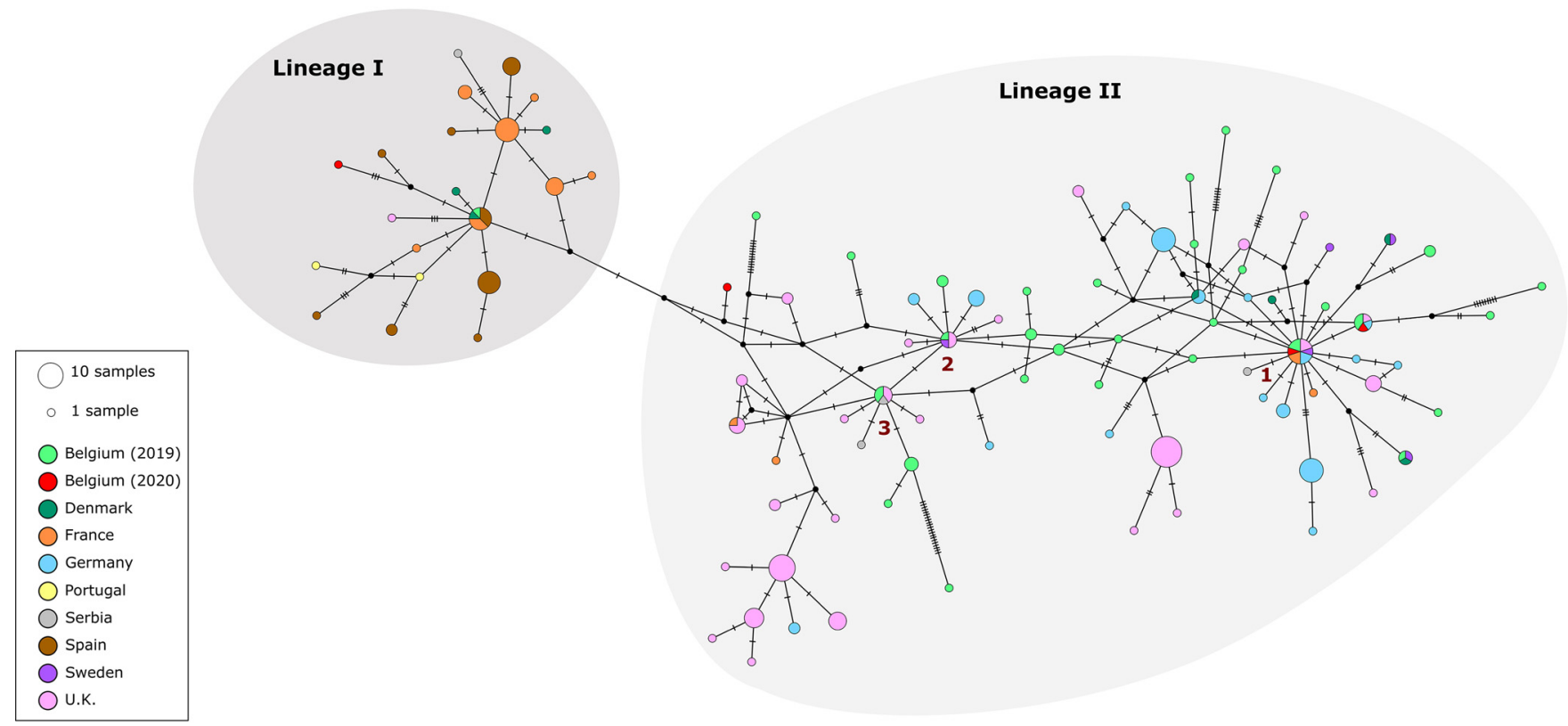

FIG 3 Median-joining network constructed with 228 COI sequences of $C x$. modestus from 9 countries in Europe. Each circle represents a haplotype. The size of the circle corresponds to the number of specimens sharing that specific haplotype. Each country is represented by a color, described in the key. Mosquito collections in Belgium are separated per year to visualize the allocation of haplotypes in the network. The gray backgrounds represent both lineages found and the distinction of these two groups. 
A)

\begin{tabular}{|c|c|c|c|}
\hline Location & Pool ID & $\begin{array}{l}\text { Mosquito } \\
\text { species }\end{array}$ & $n$ \\
\hline \multirow{6}{*}{ Urban } & \multirow{3}{*}{1} & Culex pipiens & 6 \\
\hline & & Culex modestus & 1 \\
\hline & & Culex torrentium & 1 \\
\hline & 2 & Culex pipiens & 12 \\
\hline & \multirow{2}{*}{3} & Anopheles plumbeus & 1 \\
\hline & & Culiseta annulata & 1 \\
\hline \multirow{5}{*}{ Peri-urban } & \multirow{2}{*}{4} & Culex modestus & 5 \\
\hline & & Culex pipiens & 15 \\
\hline & \multirow{2}{*}{5} & Culex modestus & 17 \\
\hline & & Culex pipiens & 3 \\
\hline & 6 & Culex modestus & 19 \\
\hline \multirow{3}{*}{ Wetlands } & 7 & Aedes cinereus & 10 \\
\hline & \multirow{2}{*}{8} & $\begin{array}{l}\text { Aedes (Ochlerotatus) } \\
\text { sticticus }\end{array}$ & 15 \\
\hline & & Culiseta morsitans & 1 \\
\hline
\end{tabular}

B)

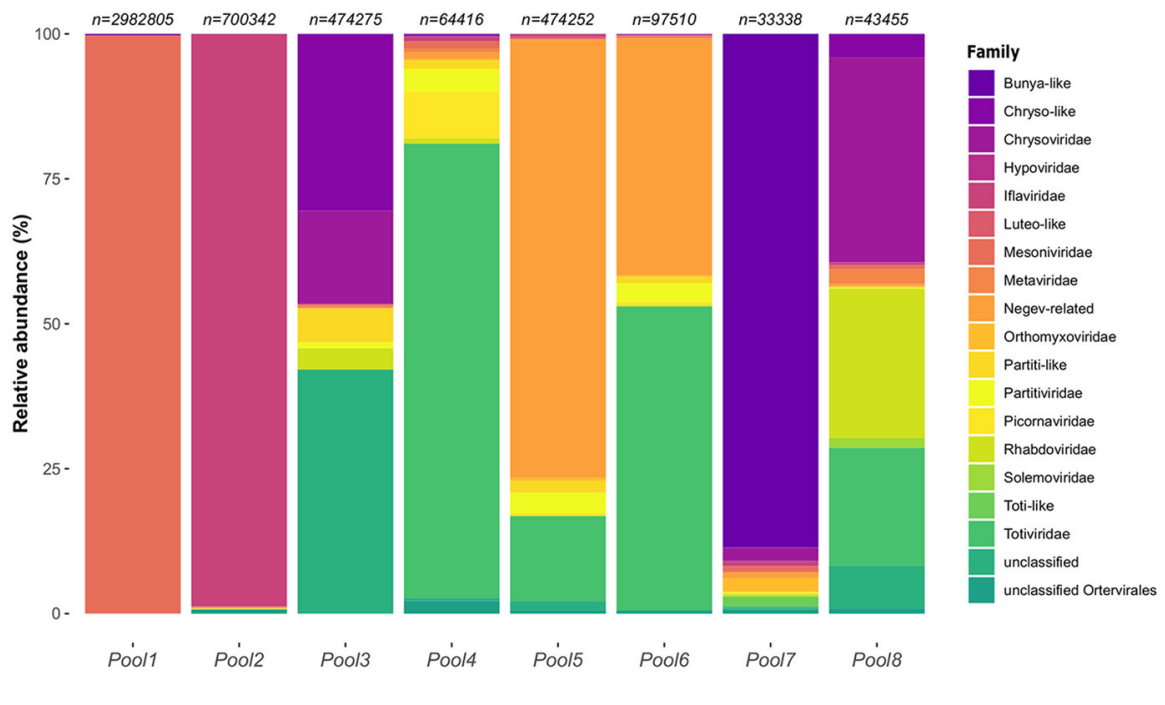

FIG 4 Summary information and viral composition of sequenced samples. (A) Location, mosquito species, and number of specimens present in each of the sequenced pools. (B) Bar plots representing the abundance of reads belonging to distinct viral families per pool. The number of eukaryotic viral reads per pool is given on top of each bar.

found in Belgium were located between three central haplotypes of lineage II, which contain samples from several countries: one is shared by Belgium, the United Kingdom, and Serbia (Fig. 3, 3); another one is shared by Belgium, the United Kingdom, and Sweden (Fig. 3, 2); and the largest one is shared by Belgium, Germany, the United Kingdom, France, and Sweden (Fig. 3, 1). Haplotypes found in mosquitoes collected in Leuven during the summer of 2020 were observed in both lineage I ( 1 haplotype) and lineage II (3 haplotypes).

A peek into the virome of Belgian mosquitoes. We characterized the virome of 107 mosquitoes' abdomens, divided into eight pools according to their morphological identification and representing the three different habitat types mentioned above (Fig. 4A). A total of 44,002,358 reads were obtained from all mosquito pools. Most reads $(21,602,296 ; 49.1 \%)$ belonged to the urban group. Mosquitoes collected in periurban and wetland areas generated 13,891,285 (31.6\%) and 8,508,777 (19.3\%) reads, respectively.

In all pools, the proportion of reads mapping to the order Diptera ranged from 40.8 to $77.7 \%$. Regarding the bacterial reads, the wetland samples had a higher mean proportion (3.83\%), followed by the urban samples, with $2.03 \%$, while the periurban samples presented $<1 \%$ of reads mapping to bacteria. The viral component was more variable, with an observable ascending trend when moving from the wetlands to periurban and urban areas. Wetland samples gathered a low proportion of viral reads $(<2 \%)$, whereas viral reads in periurban areas accounted for 1.28 to $7.19 \%$. Finally, reads mapping to the viral component comprised 7.45 to $44.69 \%$ of the urban samples.

After filtering the viral reads for eukaryotic viral species, the relative abundances in the mosquito pools are shown in Fig. 4 per viral family. The Culex pools in the urban area were completely dominated by one viral family (Mesoniviridae and Iflaviridae for pool 1 and pool 2, respectively). The periurban samples contained mostly viral reads from a Negev-related virus, namely, Yongsan negev-like virus 1, and from the Totiviridae family, with Culex inatomii totivirus being the most abundant viral species. In the wetland Ae. cinereus pool, on the other hand, an unclassified bunya-like virus was the most abundant. 


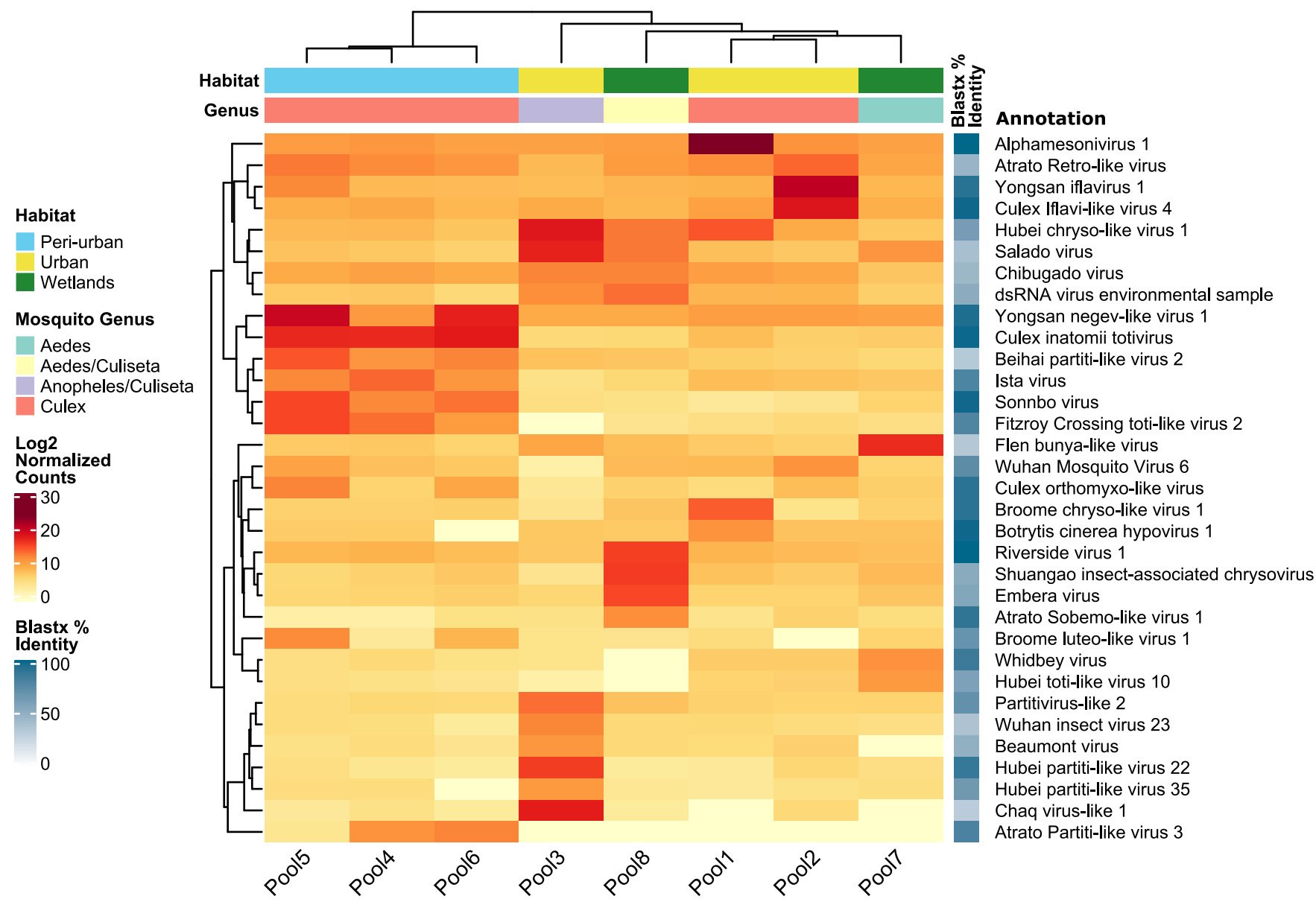

FIG 5 Heat map of normalized read counts for eukaryotic viruses. The heat map shows the normalized count on a log ${ }_{2}$ scale of reads mapping to the assembled contigs of each eukaryotic virus. Next to the taxonomic annotation, obtained by DIAMOND and KronaTools, the average BLASTx identity for all contigs representing a viral species is depicted by the shaded blue boxes. Hierarchical clustering of the columns is based on the Bray-Curtis distance matrix calculated from the normalized read counts.

Comparing the eukaryotic viromes across habitat types and mosquito genera. To compare the eukaryotic viromes of our samples, we mapped all trimmed and decontaminated reads back to the selected viral contigs, extracted the abundance table, and subsequently constructed a heat map with the normalized counts for each viral species on a $\log _{2}$ scale (Fig. 5). In total, 33 eukaryotic viral species could be detected across all samples (a viral species was considered present if it had at least one contig of $>1,000 \mathrm{bp}$ and if more than 500 reads mapped to it). According to the Bray-Curtis distance matrix, the eukaryotic viromes of the Culex mosquito pools clearly clustered together per habitat type. However, except for the periurban Culex pools, each remaining pool had a more unique viral composition, and only a small number of viruses were significantly shared between samples. Nevertheless, the periurban mosquito pools had a majority of viruses in common, such as Culex inatomii totivirus and Yongsan negevlike virus 1, which were shared with high abundances, while Ista virus, Sonnbo virus, and Fitzroy Crossing toti-like virus 2 were common in lower abundances.

Recovery of (nearly) complete meta-assembled genomes. In total, we managed to recover 9 (nearly) complete genomes of 6 viral species in our metagenomic data. These viral species belong to the following families: Totiviridae (Culex inatomii totivirus in pools 4, 5, and 6), Iflaviridae (Yongsan iflavirus 1 and Culex iflavi-like virus 4 in pool 2), Mesoniviridae (Alphamesonivirus 1 in pool 1), Rhabdoviridae (Riverside virus 1 in pool 8), and unclassified Negev-related viruses (Yongsan negev-like virus 1 in pools 5 and 6), and their phylogenetic relatedness to closely related reference strains is shown in Fig. 6 (Table S5). 
A)

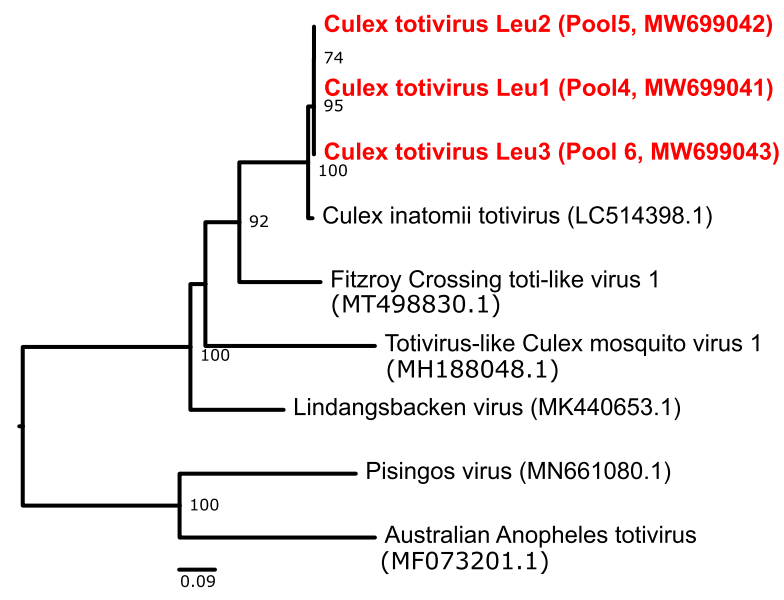

C)

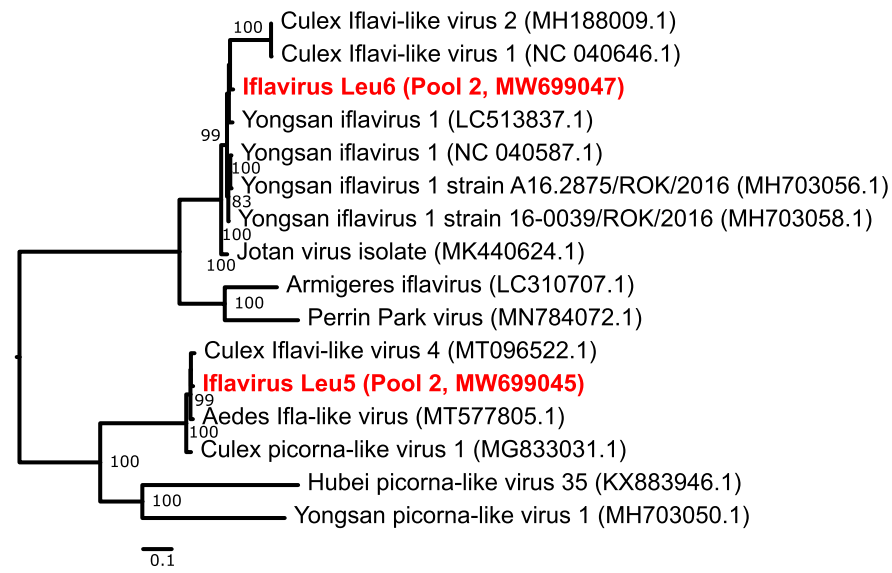

B)

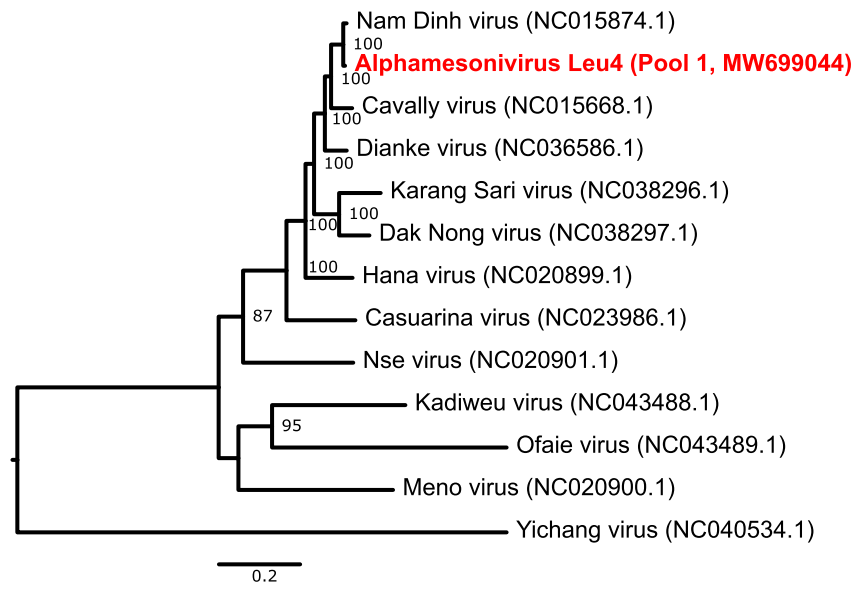

D)

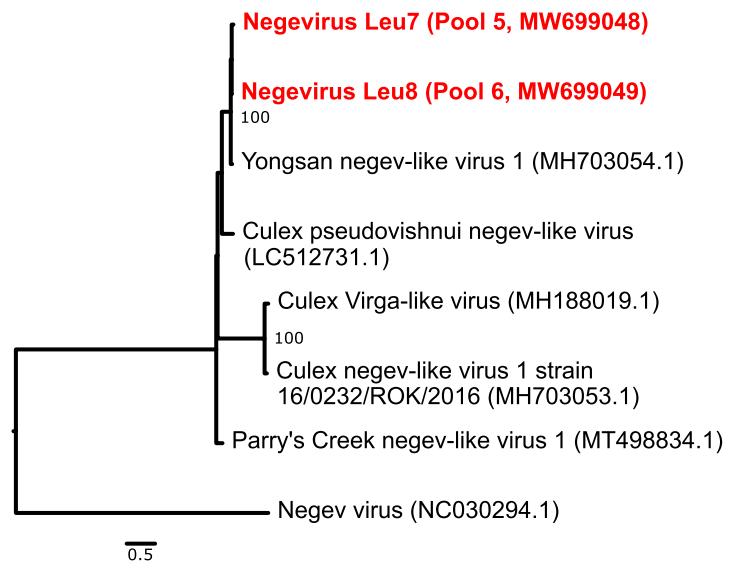

E)

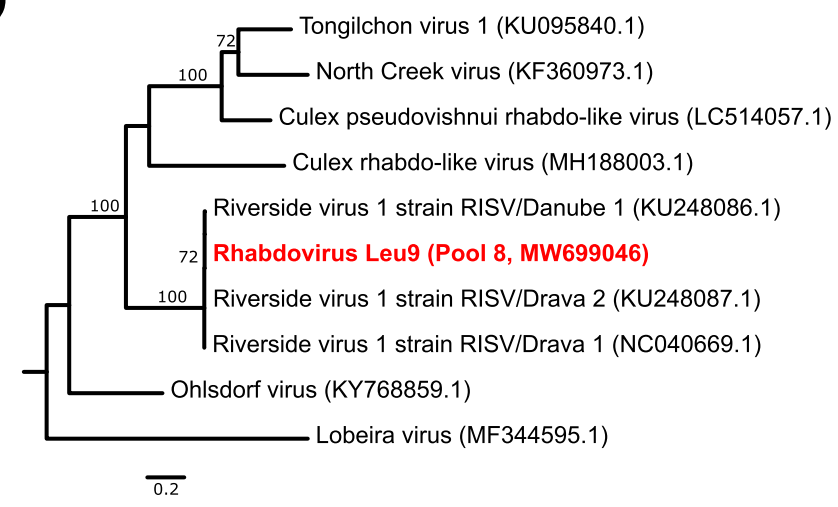

FIG 6 (Nearly) complete meta-assembled genomes identified in mosquitoes collected during the summer of 2019. Bootstrap support values are shown next to the nodes. Complete MAGs are colored in red. (A) Midpoint-rooted ML tree of all complete genomes related to Culex inatomii totivirus, selected after BLASTn analysis. (B) Midpoint-rooted ML tree of all Mesoniviridae family members. (C) Midpoint-rooted ML tree of all complete genomes related to our Yongsan iflavirus 1 and Culex iflavi-like virus 4 genomes, selected after BLASTn analysis. (D) ML tree of all complete genomes related to Yongsan negev-like virus 1, selected after BLASTn analysis. Negevirus was used as the outgroup. (E) Midpoint-rooted ML tree of all complete genomes related to the recovered Riverside virus 1. GenBank accession numbers are in parentheses.

dsRNA viruses: Totiviridae. The Totiviridae family of double-stranded RNA (dsRNA) viruses is known to infect fungi, plants, and invertebrates. In this study, we found Culex totivirus Leu1 (GenBank accession number MW699041), Leu2 (accession number MW699042), and Leu3 (accession number MW699043) (98.3\% average BLASTx identity 
with Culex inatomii totivirus [GenBank accession number LC514398.1]) in all periurban mosquito pools. This novel totivirus was recently described in $C x$. inatomii mosquitoes in Japan (32), and our findings now confirm its association with mosquitoes as a host.

Positive-sense single-stranded RNA [(+)ssRNA] viruses. (i) Mesoniviridae. When constructing a phylogenetic tree of the metagenomic assembled genomes (MAG) annotated as Alphamesonivirus 1 (99.7\% BLASTx identity [GenBank accession number MH520101.1]), together with all reference sequences of the Mesoniviridae family, our complete Alphamesonivirus Leu4 genome (GenBank accession number MW699044) formed a clade with Nam Dinh virus and Cavally virus. Both alphamesoni 1 viruses are frequently linked to mosquitoes $(33,34)$. Interestingly, all known members of the Mesoniviridae family infect mosquito hosts.

(ii) Iflaviridae. Iflaviruses are a well-known group of picorna-like viruses that exclusively infect arthropods (35). We found two complete genomes of iflaviruses (iflavirus Leu5 [GenBank accession number MW699045] and iflavirus Leu6 [accession number MW699047], having 98.3 and $97.1 \%$ BLASTx identities with Culex iflavi-like virus 4 [accession number MT096522.1] and Yongsan iflavirus 1 [accession number NC_040587.1], respectively) in an urban mosquito pool consisting entirely of $C x$. pipiens mosquitoes.

(iii) Negev-related viruses. Negevirus is a proposed taxon for diverse and geographically widely distributed insect-specific viruses isolated from mosquitoes and phlebotomine sandflies (36). We recovered 2 full genomes annotated as Yongsan negev-like virus 1 (average of $95.1 \%$ BLASTx identity [GenBank accession number MH703054.1]) from two periurban mosquito pools that mainly contained Cx. modestus mosquitoes, named Negevirus Leu7 (GenBank accession number MW699048) and Leu8 (accession number MW699049).

(-)ssRNA viruses: Rhabdoviridae. Rhabdoviruses are a diverse group of negativesense ssRNA [(-)ssRNA] viruses known to infect both vertebrates and invertebrates as well as plants (37). Riverside virus 1 was first described in Ochlerotatus sp. mosquitoes in central Europe (38), and in this study, it was also detected (98.2\% BLASTx identity [GenBank accession number KU248086.1]). Rhabdovirus Leu9 (GenBank accession number MW699046) was identified in a pool containing mostly Ochlerotatus mosquitoes. This suggests a restricted host species range as, to date and to our knowledge, this virus has not yet been found in other mosquito species or other hosts.

\section{DISCUSSION}

A national mosquito inventory between 2007 and 2010 (MODIRISK project) showed that the mosquito fauna in Belgium is composed of 23 mosquito species belonging to five traditionally recognized genera, including 21 indigenous and 2 exotic species (Ae. koreicus and Ae. japonicus) (39). The five most abundant species were Cx. pipiens (61.62\%), Coquillettidia richiardii (15.43\%), Ae. cinereus (5.04\%), Anopheles claviger (3.52\%), and Ae. vexans (2.93\%) (39). In this mosquito surveillance study performed in Leuven using BG-Sentinel traps, eight mosquito species were collected, of which seven species (Cx. pipiens, Cx. torrentium, Culiseta annulata, Culiseta morsitans, Ae. sticticus, Ae. cinereus, and Anopheles plumbeus) have been reported previously as autochthonous species of Belgium (according to the latest mosquito species checklist [6]). As only one surveillance methodology was used here, this study might undersample the mosquito diversity in Leuven. For future surveillance campaigns, additional types of mosquito traps, besides the BG-Sentinel traps (such as CDC light traps and gravid traps), will be used.

Reports on the detection of $C x$. modestus in Belgium have been absent until very recently (7). Only one larva has been detected during the latest exotic mosquito survey carried out from 2017 to 2019 (7, 40). In contrast, during our survey in 2019, Cx. modestus accounted for almost half of the mosquitoes that were collected, in three different breeding sites. In addition, $C x$. modestus mosquitoes were reconfirmed at the same collection sites in the summer of 2020. This finding suggests the establishment of this mosquito species in Belgium, potentially introduced from the United Kingdom or 
Germany. The appearance and spread of $C x$. modestus in the United Kingdom have been reported only recently as well, although this species seems to be abundantly present in certain regions based on recent surveys (2017 and 2019) (3). The hypothesis for not noticing its presence in the United Kingdom previously probably relies on the misidentification of $C x$. modestus as other mosquito species such as $C x$. torrentium (3).

Along with the introduction of a new mosquito species in a region, its potential role in the transmission of arboviruses that could cause disease in animals and humans must be evaluated. The presence of $C x$. modestus in Belgium could be problematic as it is one of the most important vectors for Dirofilaria spp. such as Dirofilaria immitis (41). Furthermore, the coexistence of $C x$. pipiens and $C x$. modestus, two important vectors, may increase the risk of transmission of WNV and USUV given the right circumstances. These two viruses are likely to cocirculate in the same habitat, where birds and $C X$. modestus mosquitoes play their roles as hosts and vectors, respectively (21). In September 2020, the enzootic transmission of WNV in the Netherlands, a neighboring country of Belgium, was confirmed for the first time by detecting simultaneously the presence of the virus in a local common whitethroat, in field-collected mosquito pools, and in humans (42). Given the establishment of $C x$. modestus in Belgium, it would be advisable to implement vector surveillance for this species. In Europe, the higher biting activity displayed by $C x$. modestus lasts from July until the beginning of October. However, given the detection of Tahyna virus (an arbovirus) in hibernating $C x$. modestus mosquitoes in France (14), winter collection can also be considered for the surveillance of mosquito-transmitted pathogens.

In order to examine the genetic structure of the $C x$. modestus population found in Leuven, we gathered mitochondrial sequences of $C x$. modestus mosquitoes collected in other countries across Europe and constructed a haplotype network using the MJ method based on 228 partial COI sequences. As recently reported (3), Cx. modestus populations across Europe are separated into two lineages. According to this network, most Belgian haplotypes were connected to haplotypes from the United Kingdom and Germany, suggesting that the mosquito population in Leuven, Belgium, could be derived from these two populations. There were three central haplotypes in lineage II that were shared by several countries. In lineage I, there is one central haplotype that was shared by individuals from Denmark, Spain, and Belgium. These data might indicate that $C X$. modestus mosquitoes belonging to both lineages are present in Belgium, suggesting the occurrence of at least two independent introduction events.

Vector competence of the mosquito can be influenced by several factors. Bacterial symbionts such as Wolbachia have the ability to hinder infection by a variety of pathogens such as chikungunya virus, dengue virus, Zika virus, WNV, and malaria-causing Plasmodium species in different mosquito species (43). It is possible that viral symbionts discovered in mosquitoes may have a similar effect. For instance, the insect-specific virus Nhumirim virus was shown to inhibit the replication of WNV, St. Louis encephalitis virus, and Japanese encephalitis virus in C6/36 cells (44). As a first step to unveil the role of viral symbionts in the mosquito's vector competence, we investigated the virome of the collected mosquitoes. Of note, no USUV or WNV was detected in the collected Culex mosquitoes. Furthermore, no Lednice virus was detected in the $C x$. modestus samples, although this mosquito species was reported to be an important Lednice Orthobunyavirus vector (13). In total, 33 eukaryotic viral species could be detected across all our samples in this study, and we recovered 9 (nearly) complete genomes of 6 viral species.

When comparing viral hits across the mosquito species and habitat types where they were collected, some similarities could be observed. Mosquito pools belonging to the same genus seemed to have more viruses in common, as shown by the clustering of the Culex mosquito pools or the distinct virome profile presented by the pool composed of Anopheles/Culiseta (pool 3) compared to the other pools. Additionally, we observed clustering of pools per habitat type. In this case, periurban mosquito pools harbored several viruses in common and in great abundances, such as Culex totivirus 
Leu1, Leu2, and Leu3 and Negevirus Leu7 and Leu8, closely related to Culex inatomii totivirus and Yongsan negev-like virus 1, respectively. Also, the 6 viral species for which a (nearly) complete genome was recovered were previously reported as, or clustered with, viruses associated with mosquitoes, which might hint at the preservation of a core mosquito virome. However, a larger sampling size is needed to suggest that the virome composition and its abundance differ according to genus, local acquisition and ecosystem, and habitat composition.

When comparing our results with those of a virome study on $C x$. quinquefasciatus and $A$ e. aegypti mosquitoes collected from Guadeloupe, which is the largest island of the French West Indies in the Caribbean, there were two virus species (Hubei toti-like virus 10 and Hubei partiti-like virus 22) found to be shared with Belgian mosquitoes (45). The fact that the same virus species was found in mosquitoes collected in Belgium and Guadeloupe could indicate a widespread global movement and/or long host-virus coevolution. Moreover, several viruses were shared with Northern European Swedish mosquitoes (Whidbey virus, Hubei partiti-like virus 22, Chaq virus-like 1, Ista virus, Wuhan mosquito virus 6 , and Sonnbo virus) $(31,46)$. At the virus family/order level, the relative virome abundance of Swedish $C x$. pipiens was dominated by the luteoviruses, orthomyxoviruses, and Nam Dinh virus. In contrast, the virome of Belgian Cx. pipiens was dominated by Iflaviridae (pool 2).

When mosquito samples are pooled, as we did in our study, the virome profile could be strongly skewed by one or a few high-titer virus infections from a single mosquito in the pool. In a study of Swedish mosquitoes, Pettersson et al. (46) reported that $30 \%$ of all reads of one of the libraries composed of $C x$. torrentium mosquitoes were annotated as Nam Dinh virus. From pool 1, we recovered the (nearly) complete genome of Alphamesonivirus Leu4, which is a member of the Mesoniviridae family that contains Nam Dinh virus. Considering what was reported in Swedish mosquitoes and that pool 1 was the only pool containing one individual of $C x$. torrentium, we suggest that Alphamesonivirus Leu4 might have been harbored by this mosquito species as it was not found in any other mosquito pool. In our study, the occurrence of more than one mosquito genus in the same pool was unintentional and resulted from pooling based on morphological identification. For further research, the use of individual mosquito bodies is recommended to perform virome characterization. The feasibility of this approach using single mosquitoes has been evaluated, and no significant differences in total read numbers and viral read proportions were found compared to pooled mosquito samples (45). In addition, processing of individual mosquitoes will more truly indicate prevalence and might provide insights into potential genotype variation between different collection sites.

In conclusion, here, we report the establishment of $C x$. modestus in the surrounding areas of the city of Leuven, Belgium. The virome of the collected mosquitoes was revealed by a metagenomics approach. As $C X$. modestus is considered to be a potential vector of WNV, USUV, and other pathogens, surveillance for this mosquito species is recommended.

\section{MATERIALS AND METHODS}

Ethics statement. Permits for periurban and wetland mosquito field collections were obtained from the leaders from the Space and Real State division and the Technical Services Department at the University of Leuven (KU Leuven). Permits for field collections in urban habitats were obtained from the landowners.

Mosquito collections. Adult mosquitoes were trapped with BG-Sentinel traps (BioGents GmbH, Germany), which were baited with BG-lure (BioGents $\mathrm{GmbH}$, Germany) and contained around $2 \mathrm{~kg}$ of dry ice in the isolated box for $\mathrm{CO}_{2}$ production. Two traps were rotated in three different habitat types (urban $\left[50^{\circ} 52^{\prime} 41^{\prime \prime} \mathrm{N}, 4^{\circ} 41^{\prime} 21^{\prime \prime} \mathrm{E}\right]$, periurban [ $50^{\circ} 51^{\prime} \mathrm{N}, 4^{\circ} 41^{\prime} \mathrm{E}$ ], and water reservoir wetlands [50 $\left.51^{\prime} \mathrm{N}, 4^{\circ} 40^{\prime} \mathrm{E}\right]$ ) in Leuven and the surrounding areas (see Fig. S1 in the supplemental material).

The parameters to determine each trap location in these habitats were similar to those described previously by Mayi et al. (47). We followed these criteria and the advice of Raf Aerts and his team at the Division of Ecology, Evolution, and Biodiversity Conservation, KU Leuven, on the selection of mosquito collection sites representing different habitat types.

Collections were performed from August to the beginning of October 2019, when the weather was 
good, avoiding strong wind or heavy rain. Every $24 \mathrm{~h}$, the traps were emptied and repositioned between sunrise and sunset of the next day. Mosquitoes were individually stored at $-80^{\circ} \mathrm{C}$ until species identification. A second collection was performed in August of 2020 in the same geographic locations as the ones described above to confirm the presence of certain species.

Species identification, sample preparation, and DNA sequencing. All collected mosquitoes were identified using morphological characteristics (48). Individual thoraces were removed using forceps for molecular identification and homogenized in $100 \mu \mathrm{l}$ of phosphate-buffered saline (PBS) using tubes with 2.8-mm ceramic beads with a Precellys Evolution homogenizer. Sample preparation was performed by lysing the homogenate at $100^{\circ} \mathrm{C}$ for $10 \mathrm{~min}$ (49). Tissue debris was removed by centrifugation at $12,000 \mathrm{rpm}$ for $3 \mathrm{~min}$, and $50 \mu \mathrm{l}$ of the supernatant was collected into a new tube. A 710-bp region of the cytochrome oxidase subunit I (COI) mitochondrial gene was the target for amplification by PCR using previously reported primers (50). The presence of the PCR product was checked on a $2 \%$ agarose gel by gel electrophoresis. DNA was purified with the Wizard SV gel and PCR clean system (Promega). The DNA concentration of the amplicon was measured by using a NanoDrop instrument (Thermo Fisher), after which samples were sent to Macrogen Europe for Sanger sequencing.

Mosquito sequence analysis and phylogeny. Sequences were edited and assembled with BioEdit version 7.2.5 (51) to obtain a single consensus sequence per mosquito. Through the BLAST tool, the generated $\mathrm{COI}$ sequences were compared to the NCBI database. Reference $\mathrm{COI}$ sequences for all mosquito species considered were selected according to methods described previously by Versteirt and colleagues (52), which employed reference sequences that were registered in the Barcode of Life Data (BOLD) systems, and downloaded from GenBank. For phylogenetic analysis, the COI sequences generated in the study and the reference sequences were aligned with MAFFT v7.471 (53) using the G-INS-I option. The resulting alignment was trimmed by using trimAl v1.4.rev15 (54) with the gappyout setting, and phylogenetic informative regions of the alignment were selected with BMGE v1.12 (55) for phylogenetic inference. Maximum likelihood (ML) trees were constructed using IQ-TREE v2.0.3 (56) with automatic selection of the best nucleotide substitution model and 1,000 ultrafast bootstrap replicates. Finally, trees were visualized using FigTree v1.4.4.

Haplotype network. Haplotype inference and nucleotide diversity were calculated in ARLEQUIN version 3.5.2.2 (57). The population genetic data were analyzed using the median-joining (MJ) network algorithm in PopART version $1.7(58,59)$. The COI sequences for $C x$. modestus included in the haplotype network were retrieved from the NCBI database. These sequences were selected based on the specimen's country of origin and the length of the COI fragment (50).

Pool design, sample preparation, and sequencing for virome analysis. The samples of mosquito abdomens were grouped in pools for sequencing according to the morphological identification of mosquito species by key points and sample location (urban, periurban, and wetlands). Abdomens were homogenized in $600 \mu \mathrm{l}$ of PBS with 2.8-mm ceramic beads with the Minilys tissue homogenizer, including a negative control (blank tube with PBS).

All pool samples were prepared using the novel enrichment technique of viromes (NetoVIR) sample preparation protocol optimized for viral metagenomics $(60,61)$. In brief, after homogenization, samples went through a centrifugation-and-filtration step (by using a $0.8-\mu \mathrm{m}$ filter; Sartorius) to remove pro- and eukaryotic organisms and large organic debris. Next, nuclease treatment (employing Benzonase and micrococcal nuclease) was applied to remove free-floating nucleic acids. Nucleic acids were extracted with the QIAamp viral RNA minikit (Qiagen) to be further randomly amplified using a modified wholetranscriptome amplification 2 (WTA2) kit procedure (Sigma-Aldrich). The products were purified, and libraries were prepared using the NexteraXT library preparation kit (Illumina). Sequencing of the samples was carried out on a NextSeq 500 high-throughput platform (Illumina) for 300 cycles.

Bioinformatic analysis and identification of eukaryotic viruses. Quality and adapter trimming on raw paired-end reads was performed using Trimmomatic v0.39 (62). Next, contamination of samples was removed with Bowtie2 v2.3.4 (63) by mapping trimmed reads to a set of contigs present in the negative controls (reagent contamination). The remaining reads were de novo assembled into contigs using metaSPAdes v3.13.0 (64). To remove redundancy in the data, contigs were filtered on a length of $1,000 \mathrm{bp}$ and subsequently clustered at $95 \%$ nucleotide identity over $80 \%$ of the length using ClusterGenomes (https://bitbucket.org/MAVERICLab/docker-clustergenomes). All contigs were classified by DIAMOND (on the sensitive setting, which can identify sequence similarities of $>40 \%$ ) (65) against the NCBI nr database (downloaded on 27 October 2020) in the sensitive mode for taxonomic annotation. KronaTools (66) was used to parse the DIAMOND output file and find the least common ancestor for each contig (based on the 25 best DIAMOND hits). Contigs annotated as eukaryotic viruses were retrieved using an in-house Python script. Pool magnitudes were obtained by mapping the trimmed and decontaminated reads to these eukaryotic viral contigs with BWA-MEM2 $(67,68)$. The resulting abundance table was further used for ecological analysis in $\mathrm{R}$ using the phyloseq (69), metagenomeSeq (70), vegan (71), and ComplexHeatmap (72) packages.

Recovery and phylogenetic analysis of (nearly) complete meta-assembled genomes. To recover full eukaryotic viral genomes in the mosquito pools, viral species were selected based on the level of genome completion after metagenomic de novo assembly. If a viral genome was not yet fully complete after assembly, the reads from the mosquito pool were mapped to a selected reference sequence (based on the annotated species using the DIAMOND and Krona tools) with BWA-MEM2 $(67,68)$. The consensus sequence was subsequently retrieved with samtools and bcftools (73). For phylogenetic analysis, relevant reference complete genome sequences were chosen after BLASTn analysis of the metagenomic assembled genomes (MAGs) and subsequently downloaded from GenBank. Alignment, trimming, model 
selection, construction, and visualization of phylogenetic trees were done as described above for mosquito $\mathrm{COI}$ sequences (see "Mosquito sequence analysis and phylogeny").

Data availability. All mosquito mitochondrial $\mathrm{COI}$ sequences obtained in this study have been deposited in GenBank under the accession numbers MW721132 to MW721173. Additionally, the raw sequence reads generated in this study are available in the NCBI Sequence Read Archive (SRA) database under BioProject accession number PRJNA705894. Virus genome sequences retrieved from our samples have been deposited in GenBank under the accession numbers MW699041 to MW699049.

\author{
SUPPLEMENTAL MATERIAL \\ Supplemental material is available online only. \\ FIG S1, PDF file, $0.2 \mathrm{MB}$. \\ TABLE S1, PDF file, $0.01 \mathrm{MB}$. \\ TABLE S2, PDF file, $0.1 \mathrm{MB}$. \\ TABLE S3, PDF file, $0.01 \mathrm{MB}$. \\ TABLE S4, PDF file, $0.01 \mathrm{MB}$. \\ TABLE S5, PDF file, $0.03 \mathrm{MB}$.
}

\title{
ACKNOWLEDGMENTS
}

This project was funded by KU Leuven (C22/18/007 and starting grant STG/19/008).

We thank Raf Aerts and his team at the Division of Ecology, Evolution, and Biodiversity Conservation, University of Leuven (KU Leuven), for their advice on the selection of mosquito collection sites representing different habitat types. Additionally, we thank Johan Neyts (Rega Institute, KU Leuven) for allowing us the use of his laboratory space and equipment for our experimental work. We also thank Katrien De Wolf from the Entomology Unit, Institute of Tropical Medicine, Belgium, for her thorough review of the manuscript and her helpful suggestions.

\section{REFERENCES}

1. Ficalbi E. 1889. Zanzara di colorito modesto. Boll Soc Entomol Ital 1:93-94.

2. European Centre for Disease Prevention and Control, European Food Safety Authority. 2020. Culex modestus-current known distribution: May 2020. European Centre for Disease Prevention and Control, Stockholm, Sweden.

3. Hernández-Triana LM, Brugman VA, Pramual P, Barrero E, Nikolova NI, Ruiz-Arrondo I, Kaiser A, Krüger A, Lumley S, Osório HC, Ignjatović-Ćupina A, Petrić D, Laure Setier-Rio M, Bødker R, Johnson N. 2020. Genetic diversity and population structure of Culex modestus across Europe: does recent appearance in the United Kingdom reveal a tendency for geographical spread? Med Vet Entomol 34:86-96. https://doi.org/10.1111/ mve.12412.

4. Bødker R, Klitgård K, Byriel DB, Kristensen B. 2014. Establishment of the West Nile virus vector, Culex modestus, in a residential area in Denmark. J Vector Ecol 39:1-3. https://doi.org/10.1111/jvec.12121.

5. Lindström A, Lilja T. 2018. First finding of the West Nile virus vector Culex modestus Ficalbi 1889 (Diptera; Culicidae) in Sweden. J Eur Mosq Control Assoc 36:1-2.

6. Boukraa S, Dekoninck W, Versteirt V, Schaffner F, Coosemans M, Haubruge E, Francis F. 2015. Updated checklist of the mosquitoes (Diptera: Culicidae) of Belgium. J Vector Ecol 40:398-407. https://doi.org/10 $.1111 /$ jvec. 12180 .

7. De Wolf K, Vanderheyden A, Deblauwe I, Smitz N, Gombeer S, Vanslembrouck A, Meganck K, Dekoninck W, De Meyer M, Backeljau T, Müller R, Van Bortel W. 2021. First record of the West Nile virus bridge vector Culex modestus Ficalbi (Diptera: Culicidae) in Belgium, validated by DNA barcoding. Zootaxa 4920:zootaxa.4920.1.7. https://doi.org/10 .11646/zootaxa.4920.1.7.

8. Brugman VA, Hernández-Triana LM, England ME, Medlock JM, Mertens PPC, Logan JG, Wilson AJ, Fooks AR, Johnson N, Carpenter S. 2017. Bloodfeeding patterns of native mosquitoes and insights into their potential role as pathogen vectors in the Thames estuary region of the United Kingdom. Parasit Vectors 10:163. https://doi.org/10.1186/s13071-017-2098-4.

9. Brugman VA, England ME, Stoner J, Tugwell L, Harrup LE, Wilson AJ, Medlock JM, Logan JG, Fooks AR, Mertens PPC, Johnson N, Carpenter S. 2017. How often do mosquitoes bite humans in southern England? A standardised summer trial at four sites reveals spatial, temporal and site- related variation in biting rates. Parasit Vectors 10:420. https://doi.org/10 .1186/s13071-017-2360-9.

10. Tran A, L'Ambert G, Balança G, Pradier S, Grosbois V, Balenghien T, Baldet T, Lecollinet S, Leblond A, Gaidet-Drapier N. 2017. An integrative eco-epidemiological analysis of West Nile virus transmission. Ecohealth 14:474-489. https://doi.org/10.1007/s10393-017-1249-6.

11. Ionicaõ AM, Zittra C, Wimmer V, Leitner N, Votýpka J, Modrý D, Mihalca AD, Fuehrer H-P. 2017. Mosquitoes in the Danube Delta: searching for vectors of filarioid helminths and avian malaria. Parasit Vectors 10:324. https://doi.org/10.1186/s13071-017-2264-8.

12. Svobodová M, Volf $P$, Votýpka J. 2015. Trypanosomatids in ornithophilic bloodsucking Diptera. Med Vet Entomol 29:444-447. https://doi.org/10 $.1111 /$ mve.12130.

13. Berčič RL, Bányai $K$, Růžek $D$, Fehér $E$, Domán $M$, Danielová $V$, Bakonyi $T$, Nowotny N. 2019. Phylogenetic analysis of lednice Orthobunyavirus. Microorganisms 7:447. https://doi.org/10.3390/microorganisms7100447.

14. Chippaux A, Rageau J, Mouchet J. 1970. Hibernation of arbovirus Tahyna in Culex modestus Fic. in France. C R Acad Hebd Seances Acad Sci D 270:1648-1650. (In French.)

15. Vaux AGC, Gibson G, Hernandez-Triana LM, Cheke RA, McCracken F, Jeffries CL, Horton DL, Springate S, Johnson N, Fooks AR, Leach S, Medlock JM. 2015. Enhanced West Nile virus surveillance in the North Kent marshes, UK. Parasit Vectors 8:91. https://doi.org/10.1186/s13071-015-0705-9.

16. Monaco F, Goffredo M, Briguglio P, Pinoni C, Polci A, lannetti S, Pinto S, Marruchella G, Di Francesco G, Di Gennaro A, Pais M, Teodori L, Bruno R, Catalani M, Ruiu A, Lelli R, Savini G. 2015. Descrizione dei focolai di West Nile disease nel 2011 nella regione Sardegna, Italia. Vet Ital 51:5-16.

17. Rudolf I, Blažejová $H$, Šebesta $O$, Mendel J, Peško J, Betášová L, Straková $P$, Šikutová S, Hubálek Z. 2018. West Nile virus (lineage 2) in mosquitoes in southern Moravia-awaiting the first autochthonous human cases. Epidemiol Mikrobiol Imunol 67:44-46.

18. Rudolf I, Rettich F, Betášová L, Imrichová K, Mendel J, Hubálek Z, Šikutová S. 2019. West Nile virus (lineage 2) detected for the first time in mosquitoes in southern Bohemia: new WNV endemic area? Epidemiol Mikrobiol Imunol 68:150-153.

19. Balenghien T, Vazeille M, Reiter P, Schaffner F, Zeller H, Bicout DJ. 2007. Evidence of laboratory vector competence of Culex modestus for West 
Nile virus. J Am Mosq Control Assoc 23:233-236. https://doi.org/10.2987/ 8756-971X(2007)23[233:EOLVCO]2.0.CO;2.

20. Balenghien T, Vazeille M, Grandadam M, Schaffner F, Zeller $H$, Reiter $P$, Sabatier P, Fouque F, Bicout DJ. 2008. Vector competence of some French Culex and Aedes mosquitoes for West Nile virus. Vector Borne Zoonotic Dis 8:589-595. https://doi.org/10.1089/vbz.2007.0266.

21. Rudolf I, Bakonyi T, Šebesta $O$, Mendel J, Peško J, Betášová L, Blažejová $H$, Venclíková K, Straková P, Nowotny N, Hubálek Z. 2015. Co-circulation of Usutu virus and West Nile virus in a reed bed ecosystem. Parasit Vectors 8:520. https://doi.org/10.1186/s13071-015-1139-0.

22. Gaibani P, Rossini G. 2017. An overview of Usutu virus. Microbes Infect 19:382-387. https://doi.org/10.1016/j.micinf.2017.05.003.

23. Weissenböck H, Bakonyi T, Rossi G, Mani P, Nowotny N. 2013. Usutu virus, Italy, 1996. Emerg Infect Dis 19:274-277. https://doi.org/10.3201/eid1902 .121191.

24. Weissenböck H, Kolodziejek J, Url A, Lussy H, Rebel-Bauder B, Nowotny N. 2002. Emergence of Usutu virus, an African mosquito-borne Flavivirus of the Japanese encephalitis virus group, central Europe. Emerg Infect Dis 8:652-656. https://doi.org/10.3201/eid0807.020094.

25. Becker N, Jöst H, Ziegler U, Eiden M, Höper D, Emmerich P, Fichet-Calvet E, Ehichioya DU, Czajka C, Gabriel M, Hoffmann B, Beer M, Tenner-Racz K, Racz P, Günther S, Wink M, Bosch S, Konrad A, Pfeffer M, Groschup MH, Schmidt-Chanasit J. 2012. Epizootic emergence of Usutu virus in wild and captive birds in Germany. PLoS One 7:e32604. https://doi.org/10.1371/ journal.pone.0032604.

26. Oude Munnink BB, Münger E, Nieuwenhuijse DF, Kohl R, van der Linden A, Schapendonk CME, van der Jeugd H, Kik M, Rijks JM, Reusken CBEM, Koopmans M. 2020. Genomic monitoring to understand the emergence and spread of Usutu virus in the Netherlands, 2016-2018. Sci Rep 10:2798. https://doi.org/10.1038/s41598-020-59692-y.

27. Rouffaer LO, Steensels M, Verlinden M, Vervaeke M, Boonyarittichaikij R, Martel A, Lambrecht B. 2018. Usutu virus epizootic and Plasmodium coinfection in Eurasian blackbirds (Turdus merula) in Flanders, Belgium. J Wildl Dis 54:859-862. https://doi.org/10.7589/2017-07-163.

28. Benzarti E, Sarlet M, Franssen M, Cadar D, Schmidt-Chanasit J, Rivas JF, Linden A, Desmecht D, Garigliany M. 2020. Usutu virus epizootic in Belgium in 2017 and 2018: evidence of virus endemization and ongoing introduction events. Vector Borne Zoonotic Dis 20:43-50. https://doi.org/ 10.1089/vbz.2019.2469.

29. Shi C, Liu Y, Hu X, Xiong J, Zhang B, Yuan Z. 2015. A metagenomic survey of viral abundance and diversity in mosquitoes from Hubei province. PLoS One 10:e0129845. https://doi.org/10.1371/journal.pone.0129845.

30. Bolling BG, Weaver SC, Tesh RB, Vasilakis N. 2015. Insect-specific virus discovery: significance for the arbovirus community. Viruses 7:4911-4928. https://doi.org/10.3390/v7092851.

31. Öhlund $P$, Hayer J, Lundén H, Hesson JC, Blomström A-L. 2019. Viromics reveal a number of novel RNA viruses in Swedish mosquitoes. Viruses 11:1027. https://doi.org/10.3390/v11111027.

32. Faizah AN, Kobayashi D, Isawa H, Amoa-Bosompem M, Murota K, Higa $Y$, Futami K, Shimada S, Kim KS, Itokawa K, Watanabe M, Tsuda Y, Minakawa N, Miura K, Hirayama K, Sawabe K. 2020. Deciphering the virome of Culex vishnui subgroup mosquitoes, the major vectors of Japanese encephalitis, in Japan. Viruses 12:264. https://doi.org/10.3390/v12030264.

33. Zhou J, Jin Y, Chen Y, Li J, Zhang Q, Xie X, Gan L, Liu Q. 2017. Complete genomic and ultrastructural analysis of a Nam Dinh virus isolated from Culex pipiens quinquefasciatus in China. Sci Rep 7:271. https://doi.org/10 .1038/s41598-017-00340-3.

34. Zirkel F, Kurth A, Quan PL, Briese T, Ellerbrok H, Pauli G, Leendertz FH, Lipkin WI, Ziebuhr J, Drosten C, Junglen S. 2011. An insect nidovirus emerging from a primary tropical rainforest. mBio 2:e00077-11. https:// doi.org/10.1128/mBio.00077-11.

35. van Oers M. 2008. Iflavirus, p 42-46. In Mahy BWJ, Van Regenmortel MHV (ed), Encyclopedia of virology, 3rd ed. Academic Press, Oxford, United Kingdom.

36. Vasilakis N, Forrester NL, Palacios G, Nasar F, Savji N, Rossi SL, Guzman H, Wood TG, Popov V, Gorchakov R, Gonzalez AV, Haddow AD, Watts DM, da Rosa APAT, Weaver SC, Lipkin WI, Tesh RB. 2013. Negevirus: a proposed new taxon of insect-specific viruses with wide geographic distribution. J Virol 87:2475-2488. https://doi.org/10.1128/JVI.00776-12.

37. Kuzmin IV, Novella IS, Dietzgen RG, Padhi A, Rupprecht CE. 2009. The rhabdoviruses: biodiversity, phylogenetics, and evolution. Infect Genet Evol 9:541-553. https://doi.org/10.1016/j.meegid.2009.02.005.

38. Reuter G, Boros Á, Pál J, Kapusinszky B, Delwart E, Pankovics P. 2016. Detection and genome analysis of a novel (dima)rhabdovirus (Riverside virus) from Ochlerotatus sp. mosquitoes in central Europe. Infect Genet Evol 39:336-341. https://doi.org/10.1016/j.meegid.2016.02.016.

39. Versteirt V, Boyer S, Damiens D, De Clercq EM, Dekoninck W, Ducheyne E, Grootaert P, Garros C, Hance T, Hendrickx G, Coosemans M, Van Bortel W. 2013. Nationwide inventory of mosquito biodiversity (Diptera: Culicidae) in Belgium, Europe. Bull Entomol Res 103:193-203. https://doi.org/10 $.1017 /$ S0007485312000521.

40. Deblauwe I, De Wolf K, Smitz N, Vanslembrouck A, Schneider A, De Witte J, Verlé I, Dekoninck W, De Meyer M, Backeljau T, Gombeer S, Meganck K, Van Bourgonie Y-R, Vanderheyden A, Müller R, Van Bortel W. 2020. Monitoring of exotic mosquitoes in Belgium (MEMO). Final report phase 7 part 1: MEMO results. Institute of Tropical Medicine, Antwerp, Belgium.

41. Rossi L, Pollono F, Meneguz PG, Cancrini G. 1999. Quattro specie di culicidi come possibili vettori di Dirofilaria immitis nella risaia piemontese. Parassitologia 41:537-542.

42. Vlaskamp DR, Thijsen SF, Reimerink J, Hilkens P, Bouvy WH, Bantjes SE, Vlaminckx BJ, Zaaijer H, van den Kerkhof HH, Raven SF, Reusken CB. 2020. First autochthonous human West Nile virus infections in the Netherlands, July to August 2020. Euro Surveill 25:2001904. https://doi.org/10.2807/ 1560-7917.ES.2020.25.46.2001904.

43. Caragata EP, Dutra HLC, Moreira LA. 2016. Inhibition of Zika virus by Wolbachia in Aedes aegypti. Microb Cell 3:293-295. https://doi.org/10.15698/ mic2016.07.513.

44. Kenney JL, Solberg OD, Langevin SA, Brault AC. 2014. Characterization of a novel insect-specific flavivirus from Brazil: potential for inhibition of infection of arthropod cells with medically important flaviviruses. J Gen Virol 95:2796-2808. https://doi.org/10.1099/vir.0.068031-0.

45. Shi C, Beller L, Deboutte W, Yinda KC, Delang L, Vega-Rúa A, Failloux AB, Matthijnssens J. 2019. Stable distinct core eukaryotic viromes in different mosquito species from Guadeloupe, using single mosquito viral metagenomics. Microbiome 7:121. https://doi.org/10.1186/s40168-019-0734-2.

46. Pettersson JH, Shi M, Eden JS, Holmes EC, Hesson JC. 2019. Meta-transcriptomic comparison of the RNA viromes of the mosquito vectors Culex pipiens and Culex torrentium in northern Europe. Viruses 11:1033. https://doi.org/10.3390/v11111033.

47. Mayi MPA, Bamou R, Djiappi-Tchamen B, Fontaine A, Jeffries CL, Walker T, Antonio-Nkondjio C, Cornel AJ, Tchuinkam T. 2020. Habitat and seasonality affect mosquito community composition in the West Region of Cameroon. Insects 11:312. https://doi.org/10.3390/insects11050312.

48. Becker N, Petrić D, Zgomba M, Boase C, Madon M, Dahl C, Kaiser A. 2010. Mosquitoes and their control, 2nd ed, p 91-111. Springer, Berlin, Germany.

49. Ander M, Troell K, Chirico J. 2013. Barcoding of biting midges in the genus Culicoides: a tool for species determination. Med Vet Entomol 27:323-331. https://doi.org/10.1111/j.1365-2915.2012.01050.x.

50. Folmer O, Black M, Hoeh W, Lutz R, Vrijenhoek R. 1994. DNA primers for amplification of mitochondrial cytochrome c oxidase subunit I from diverse metazoan invertebrates. Mol Mar Biol Biotechnol 3:294-299.

51. Hall TA. 1999. BioEdit: a user-friendly biological sequence alignment editor and analysis program for Windows 95/98/NT. Nucleic Acids Symp Ser (Oxf) 41:95-98.

52. Versteirt V, Nagy ZT, Roelants $P$, Denis L, Breman FC, Damiens D Dekoninck W, Backeljau T, Coosemans M, Van Bortel W. 2015. Identification of Belgian mosquito species (Diptera: Culicidae) by DNA barcoding. Mol Ecol Resour 15:449-457. https://doi.org/10.1111/1755-0998.12318.

53. Katoh K, Standley DM. 2013. MAFFT multiple sequence alignment software version 7: improvements in performance and usability. Mol Biol Evol 30:772-780. https://doi.org/10.1093/molbev/mst010.

54. Capella-Gutiérrez S, Silla-Martínez JM, Gabaldón T. 2009. trimAl: a tool for automated alignment trimming in large-scale phylogenetic analyses. Bioinformatics 25:1972-1973. https://doi.org/10.1093/bioinformatics/btp348.

55. Criscuolo A, Gribaldo S. 2010. BMGE (Block Mapping and Gathering with Entropy): a new software for selection of phylogenetic informative regions from multiple sequence alignments. BMC Evol Biol 10:210 https://doi.org/10.1186/1471-2148-10-210.

56. Nguyen LT, Schmidt HA, Von Haeseler A, Minh BQ. 2015. IQ-TREE: a fast and effective stochastic algorithm for estimating maximum-likelihood phylogenies. Mol Biol Evol 32:268-274. https://doi.org/10.1093/molbev/ msu300.

57. Excoffier L, Lischer HEL. 2010. Arlequin suite ver 3.5: a new series of programs to perform population genetics analyses under Linux and Windows. Mol Ecol Resour 10:564-567. https://doi.org/10.1111/j.1755-0998 .2010.02847.x. 
58. Bandelt HJ, Forster P, Röhl A. 1999. Median-joining networks for inferring intraspecific phylogenies. Mol Biol Evol 16:37-48. https://doi.org/10 .1093/oxfordjournals.molbev.a026036.

59. Leigh JW, Bryant D. 2015. POPART: full-feature software for haplotype network construction. Methods Ecol Evol 6:1110-1116. https://doi.org/10 .1111/2041-210X.12410.

60. Conceição-Neto $N$, Zeller $M$, Lefrère H, De Bruyn $P$, Beller L, Deboutte $W$ Yinda CK, Lavigne R, Maes P, Van Ranst M, Heylen E, Matthijnssens J. 2015. Modular approach to customise sample preparation procedures for viral metagenomics: a reproducible protocol for virome analysis. Sci Rep 5:16532. https://doi.org/10.1038/srep16532.

61. Shi C. 2020. Unbiased analyses of virome in mosquito vectors and their association with the transmission potential of pathogenetic arboviruses. PhD thesis. KU Leuven, Leuven, Belgium.

62. Bolger AM, Lohse M, Usadel B. 2014. Trimmomatic: a flexible trimmer for Illumina sequence data. Bioinformatics 30:2114-2120. https://doi.org/10 .1093/bioinformatics/btu170.

63. Langmead B, Salzberg SL. 2012. Fast gapped-read alignment with Bowtie 2. Nat Methods 9:357-359. https://doi.org/10.1038/nmeth.1923.

64. Nurk S, Meleshko D, Korobeynikov A, Pevzner PA. 2017. MetaSPAdes: a new versatile metagenomic assembler. Genome Res 27:824-834. https:// doi.org/10.1101/gr.213959.116.

65. Buchfink B, Xie C, Huson DH. 2015. Fast and sensitive protein alignment using DIAMOND. Nat Methods 12:59-60. https://doi.org/10.1038/nmeth .3176
66. Ondov BD, Bergman NH, Phillippy AM. 2011. Interactive metagenomic visualization in a Web browser. BMC Bioinformatics 12:385. https://do .org/10.1186/1471-2105-12-385.

67. Li H, Durbin R. 2009. Fast and accurate short read alignment with Burrows-Wheeler transform. Bioinformatics 25:1754-1760. https://doi.org/10 .1093/bioinformatics/btp324.

68. Vasimuddin M, Misra S, Li H, Aluru S. 2019. Efficient architecture-aware acceleration of BWA-MEM for multicore systems, p 314-324. In Proceedings of the 2019 IEEE International Parallel and Distributed Processing Symposium (IPDPS), Rio de Janeiro, Brazil. IEEE, Piscataway, NJ. https://doi .org/10.1109/IPDPS.2019.00041.

69. McMurdie PJ, Holmes S. 2013. phyloseq: an R Package for reproducible interactive analysis and graphics of microbiome census data. PLoS One 8: e61217. https://doi.org/10.1371/journal.pone.0061217.

70. Paulson JN, Stine OC, Bravo HC, Pop M. 2013. Differential abundance analysis for microbial marker-gene surveys. Nat Methods 10:1200-1202. https://doi.org/10.1038/nmeth.2658.

71. Dixon P. 2003. VEGAN, a package of R functions for community ecology. J Veg Sci 14:927-930. https://doi.org/10.1111/j.1654-1103.2003.tb02228.x.

72. Gu Z, Eils R, Schlesner M. 2016. Complex heatmaps reveal patterns and correlations in multidimensional genomic data. Bioinformatics 32:2847-2849. https://doi.org/10.1093/bioinformatics/btw313.

73. Li H, Handsaker B, Wysoker A, Fennell T, Ruan J, Homer N, Marth G, Abecasis G, Durbin R, 1000 Genome Project Data Processing Subgroup. 2009. The Sequence Alignment/Map format and SAMtools. Bioinformatics 25:2078-2079. https://doi.org/10.1093/bioinformatics/btp352. 